\title{
An Adaptive Course Materials Selection into a Multi- agent based e-Learning System
}

\author{
Vanco Cabukovski \\ Faculty of Natural Sciences and Mathematics \\ Ss. Cyril and Methodius University \\ 1000 Skopje, Republic of Macedonia
}

\author{
Roman Golubovski \\ Faculty of Natural Sciences and Mathematics \\ Ss. Cyril and Methodius University \\ 1000 Skopje, Republic of Macedonia
}

\begin{abstract}
Modern information and communication technologies are emerging in all segments of life, including education. Affordable digitalization and low-budget content development allow for virtually unlimited access to shared knowledge. Formal education is already more or less supported by such additional material everywhere. Methodologies are developed to support automation of content management, as well as to tailor-make material suggestions and delivery according to individual learner's preferences. Such an adaptive approach inevitably faces challenges like following individual learning habits and behaviour, maintaining an up-to-date knowledge and evaluation coordinative instances, along with credible low-budget media development keeping pace with the curricula evolution. An integrated Intelligent Agent-Based University Information System (IABUIS) is successfully implemented at the Faculty of Natural Sciences and Mathematics with the University Ss. Cyril and Methodius, in Skopje. An AeLS (Adaptive e-Learning System) within it, attempts to propagate faster individual learning curves by employing agent-based system consisted of agent-based algorithms for adaptive interaction with the consumers (students), and adaptive content/course selection and delivery of appropriate material intended for improved knowledge acquisition, thus better learning results - subject of official examination. This paper presents latest improvements in the user - AeLS interaction point.
\end{abstract}

\section{General Terms}

E-Learning, Multi-agents, Course materials, Adaptability, Fuzzy expert system, Content management system.

\section{Keywords}

Adaptive e-learning system, Intelligent agents, Integrated university information system.

\section{INTRODUCTION}

Adaptation is the new trend in the modern e-Learning concepts (AeLS) aimed to produce more effective learning curve by tailoring a course's curriculum to individuals' specific preferences. These individual student preferences are evaluated by the AeLS in an automated manner, by following student's activities in the formal e-Learning system (lecturing material) and in complementary informal Content Management System (CMS) containing carefully gathered supplement material (multimedia supplements). Adapted is the presentation of information and overall linkage structure to individual users in accordance to their knowledge and behavior.

Adaptive e-Learning is based on the assumption that each learner has different learner characteristics and that different educational settings can be more suitable for one type of learner than for another [1]. When course content can be provided in a flexible way, adapted to individual learners' characteristics through the e-Learning system, the system can deliver the course content so that it capitalizes on the learner's characteristics in order to optimize the learning outcome $[2,3,4,5]$

An AeLS is able to keep track of usage and to accommodate content automatically for each of the users, for the best learning result, which in turn is supported by a student model built from student's goals, preferences, and knowledge. The student model is used to adapt the interaction mode of the eLearning system according to the user's needs $[2,4]$.

The Adaptive Content/Course Delivery applied to the system presented in this paper constitutes the most common and widely used collection of adaptation techniques applied in learning environments today. It optimises the fit between course contents and user characteristics / requirements, so that the optimal learning result is obtained. A methodology for development of additional low-budget digital content as an additional alternative fragments of course material for adaptive selection and composing of the course to individual users in accordance with their knowledge and behaviour, the influence of the low-budget digital contents in the increase of the quality of the students' experience, and the cost analysis of the additional digital content are given in [6].

In this paper, presented is an AeLS successfully implemented at the Faculty of Natural Sciences and Mathematics with the University Ss. Cyril and Methodius, as an advancement from the previous agent-based eLS IABUIS (Integrated Intelligent Agent Based University Information System). The main point of interest would be an AeLS (Adaptive e-Learning System) within it which attempts to propagate faster individual learning curves by employing agent-based system consisted of agent-based algorithms for adaptive interaction with the consumers (students), and adaptive content/course selection and delivery of appropriate material (supplements) intended for improved knowledge acquisition, thus better learning results - subject of official examination. An AeLS is developed based on adaptive selection of alternative (fragments of) course material developed as low-budget content with a main goal alternatively to give the students additional material in order successfully to gain and implement the knowledge. In the paper would be presented the latest improvements in the Personal Filtering Assistant agent, the user - AeLS interaction point.

Such an adaptive eLS is by definition demanding of intellectual and material effort, directly implicating round-theclock maintenance. Therefore, one of the crucial factors in its conceptualizing, dimensioning and realization is the financial one. The making of the supplements (often synchronized video and audio content) would normally be expensive. 
However, required technologies are already affordable at little or no cost at all - usually open source or freeware, thus allowing for cheap low-budget multimedia production. These circumstances support the CMS of the below described AeLS to be continuously updated and maintained according to the trended requirements. This kind of low-budget CMS proves almost immediately efficiency and usefulness in supporting students' advancement in their studies through successful overcoming the learning curriculum in both the theoretical as well as the practical courses like Object and Visual Programming, Compilers, etc.

\section{AN INTEGRATED INTELLIGENT UNIVERSITY INFORMATION SYSTEM (IABUIS)}

The model of IABUIS includes four processes: student administrative information management, library information management, e-learning information management and university administrative information management process. The IABUIS is an e-university environment in a provision of adaptive agent based e-learning concepts, technology and digital content unification, digital libraries standardization and information management integration $[7,8,9,10,11]$.

The IABUIS system was created as an integrated system, aiming to computerize all university processes at our faculty. In our model, each subdivision (institute or department) is represented by an Intranet, while all subdivisions together constitute the University Intranet. The University Intranet with a few external connections consist the University Extranet which is connected to the Internet on several points.

The client-server architecture is used for the university information system. Professors and university staff have many different type of work to prepare. University resources (time, money, classrooms etc.) need to be allocated in a detailed manner by staff. Scheduling and planning of exams must be done in exact time by professors. The huge production of teaching material, administrative and teaching data and library's collections are integrated on university level in knowledge and information university system, fully standardized and made compatible on state and global level [9].

\section{THE ADAPTIVE E-LEARNING SYSTEM - AELS}

The structure of the adaptive e-learning system with an embedded agent infrastructure is presented with the following model in figure 1. It is an adaptive agent based extension to the existing distance educational system MATHEIS (MATHematical Electronic Interactive System). MATHEIS is an educational system for learning mathematics and informatics for pupils and students [11, 12]. This system has been successfully integrated into ORACLE iLearning management system at the Faculty of Natural Sciences and Mathematics in Skopje and extended into Sakai e-learning environment. And a CMS (Content Management System) is integrated with the two, to host multimedia supplements to existing courses.

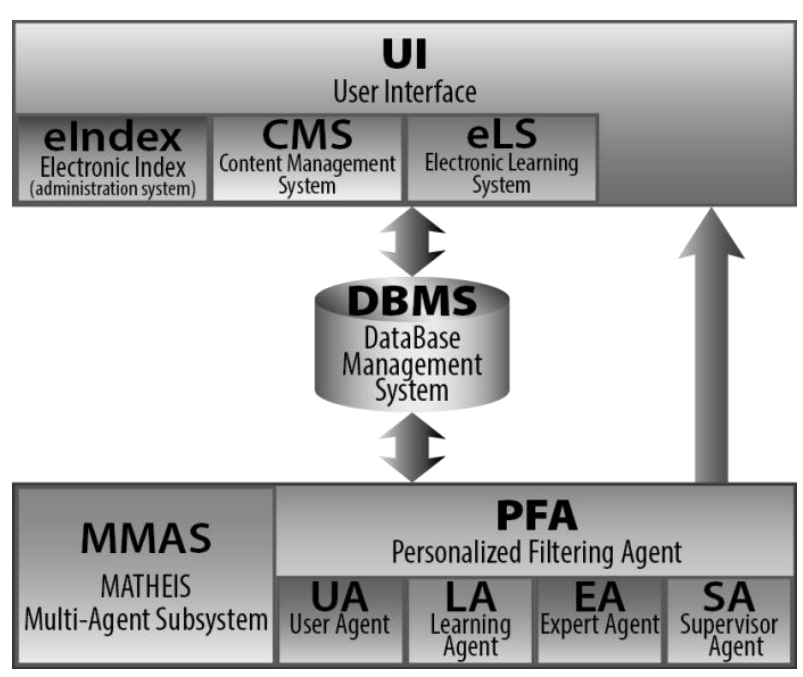

Figure 1: The AeLS structure

An agent extension of MATHEIS empowers the system with the following features: monitoring the students behavior and interests at the system; determining the student's skill level; enabling cooperative task resolution among students; enabling different views of the services and content according to the student's skills and requirements (adaptability); notifying the students when the newest tests for appropriate level are available; presenting the tests to the students and estimating the received results; automatically updating of the student's levels depending on the estimated results, etc.

The general idea behind this concept is to provide the students with supplemental material in support to steeper learning curves, submitted to the AeLS via the CMS, and approved by the lecturers. The CMS is constantly monitoring the overall progress of all students with their semestral courses and updates the supplements ranking list accordingly. Students are also evaluated periodically through test examination and ranked accordingly. Adaptation is then implemented with an algorithm which basically suggests higher ranked supplements set to lower ranking students, and more relaxed content to higher ranking students. This adaptive aspect of the eLS (AeLS) is implemented by the PFA subsystem.

\subsection{The MATHEIS subsystem}

The agent-based structure of the AeLS core (MATHEIS Multi-Agent Subsystem) is given in figure 2.

The system is able adaptively to assist into filtering of the educational material according to the UPA (User Profile Agent) and student's activities in the communication with MATHEIS basic services recorded by the PAA (Personalized Activity Agent). The Personalized Content Viewing Agent (PCVA) is responsible for the adaptive interaction and adaptive content/course delivery - this enhances the usability of material and thus make the e-Learning system more effective, which improves the students' acquisition of knowledge and lead to better learning results. All three agents collaborate among them sharing distributed agent knowledge and learning rules $[13,14]$. 


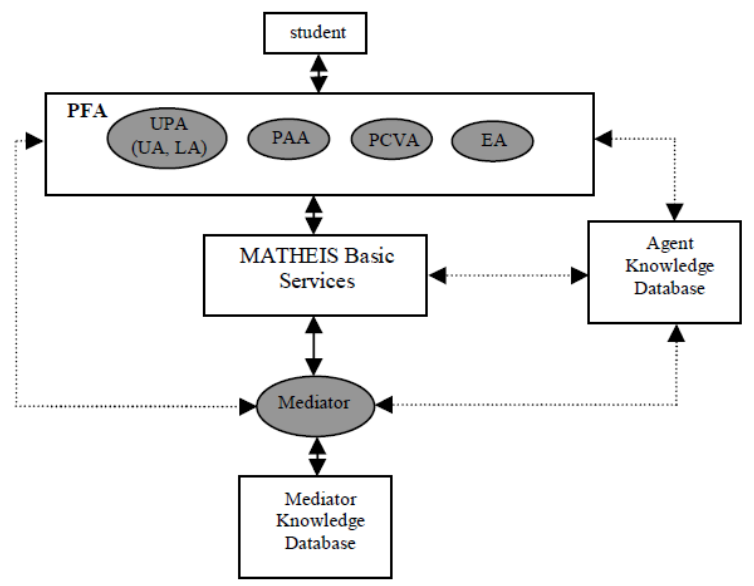

Figure 2: The agent-based structure of MATHEIS

The Mediator is responsible for the student learning model, database of the student's grades, degree levels, preferences, abilities, aptitudes, etc. This agent communicates with the Mediator knowledge database, generated during the educational process on the system.

The Personalized Filtering Assistant (PFA) segment follows the student's activities. It is responsible for the adaptive selection and display of the content and adaptive interaction. The PFA is trained for each student to make the right content selection appropriate to the student's abilities and aptitudes. Since the student's abilities and aptitudes are not assumed to be constant overtime, the system is able via pre-selected tests to notice that the student's abilities and aptitudes have been changed. The system adapts its behavior in response to these changes.

\subsection{Functional MMAS structure}

MMAS (MATHEIS Multy-Agent System) as shown in figure 3 is consisted of four conceptual subsystems: The User Agents Community; the Level Maintenance Subsystem; the Supervisory Subsystem and the Fuzzy Expert Subsystem. For detailed description of the structure of MMAS as well as relations between agents in MMAS read [8].

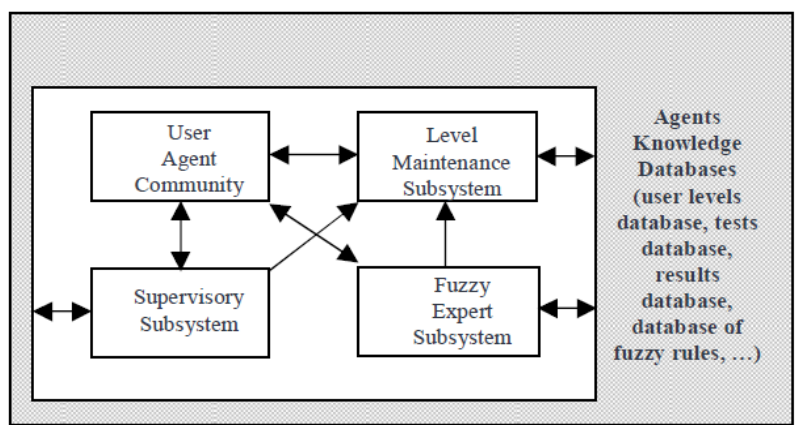

Figure 3: Relationship among the MMAS functional components

The User Agent Community subsystem is consisted of agents representing every particular user registered in the system. It serves as an interface between the users and the MMAS. UA adapts the user view through filtering according to evaluated level.

The Level Maintenance Subsystem is wrapped around a single agent called Level Agent (LA). LA evaluates and maintains the user levels and the user levels database. The LA is triggered by the UA to determine the current user level. It maintains the user level database, so is also able to track the history of level variations for every user.

The Supervisory Subsystem is also consisted of a single Supervisor Agent (SA) monitoring and coordinating the rest of the agents, making suggestions about user levels, notifying for new test arrival, maintaining the test database, and analyzing the results database. It is responsible and for adaptive interaction and adaptive content/course delivery.

The Fuzzy Expert System is driven by the Expert Agent associated with its Knowledge database of fuzzy rules for estimation of the user results and determination of the user's appropriate level.

\subsection{The Personal Filtering Assistant Agent}

The adaptive behaviour of a learning environment is implemented in the PFA agent, and has numerous manifestations. The broad and partially overlapping categories are: adaptive interaction, adaptive content/course delivery, content discovery and assembly, and adaptive collaboration support.

The Adaptive Content/Course Delivery applied to the system optimises the fit between course contents and user characteristics / requirements, so that the optimal learning result is obtained.

The fundamental task of the PFA agent is to continuously evaluate both, the individual knowledge level of each student as (s)he advances through the course's curricula on one hand, as well as the "most appropriate" supplement material that had proved to be most helpful for that particular student level, on the other hand. So basically, parallel ranking lists of students (by level) and supplements (by significance) are maintained and used for matching against each other, in direct support of the adaptation process itself.

\section{THE ROLE OF THE CONTENT MANAGEMENT SYSTEM}

The supplements (portions of particular course supporting/related content) are multimedia units managed in the Database (DBMS) by a Content Management System (CMS). The CMS is integrated in the faculty's AeLS with its own UI through which its portion of the integrated DB is updated and maintained. Anybody can submit a supplement, however only a course corresponding lecturer can admit it for usage after reviewing it.

The CMS just like any other DBMS software archives every single action within its working domain in detailed log files containing: the action itself (upload, download, approved, etc.); the user who performed it (student, lecturer); the content (supplement) affected; timestamp of the action, etc. These detailed logs allow for the PFA to keep track of what supplement had been downloaded by which student within a certain course. The PFA also uses the eIndex system to keep track of which students had passed certain exams and with what grades. By combining these DB entries with the CMS logs the PFA can easily calculate a precise contribution of every single supplement to students' success of its corresponding course.

Calculated contribution of all supplements belonging to same course allows the PFA to build and maintain a supplements list ranking highest those that contribute most, i.e. downloads that helped most students to pass examination and/or with 
highest grades. The rank lists for all courses are updated on semestral basis - after the semestral exams.

As being said, students are also evaluated periodically through test examination and ranked accordingly. Adaptation is then implemented with an algorithm which basically suggests higher ranked supplements set to lower ranking students, and more relaxed content to higher ranking students.

\section{THE ROLE OF THE FUZZY EXPERT SYSTEM}

In order to be able to adapt supplements' curricula to the student, the PFA has to evaluate student's skill level periodically by test examination. The nature of the level estimation process requires a fuzzy approach, which is the job of the Fuzzy Expert System.

Namely, in the problem solving process not only the final result is important. Thus, often is not enough to esteem the test solution as true or false, but also partial truth of the solution needs to be considered. Additional problem is the different ways of representing same result. Things become more complicated when tests are consisted of more than single task, so the estimation of the test depend on all tasks' solutions.

Fuzzy logic is particularly applicable to the individual student level estimation since problems of partial truth are very common in the real world. It is a kind of generalization of the two-element Boolean logic with values between 0 and 1 . Fuzzy subset $\mathrm{P}$ of a set $\mathrm{S}$ is defined as mapping $\mathrm{f}: \mathrm{S} \rightarrow[0,1]$ where the second element of the ordered pairs $(x, t): x \in S, t \in$ $[0,1]$ obtained from the mapping represents the degree of membership in the subset $\mathrm{P}$, or the degree of truth of the statement "x is in $\mathrm{P}$ ". The set $\mathrm{S}$ is referred to as universe of discourse, and $\mathrm{f}$ is a membership function of $\mathrm{P}$.

In the PFA context, the universe of discourse $\mathrm{S}$ is consisted of tests $\mathrm{T}$ for user skills estimation. A test is represented as a questionnaire of $n$ tasks, where for each task several solutions are proposed, only one of which is correct. This means that a test can be viewed as an $n$-dimensional vector of tasks $\mathrm{T}=\left(t_{l}\right.$, $\left.\ldots, t_{n}\right)$, and the solution of the test as an $\mathrm{n}$-dimensional vector of results $\mathrm{R}=\left(r_{1}, \ldots, r_{n}\right)$, where $r_{i} \in\{0,1\}$ and $r_{i}=1$ means correct user reply and $r_{i}=0$ means incorrect result. For every task in the test a weighting factor $k$ is assigned, where the condition $k_{1}+k_{2}+\ldots+k_{n}=n$ must be satisfied. Without losing generality it can be assumed that $m$ correct results $(m \leq n)$ appear at the first $\mathrm{m}$ places in both vectors $\mathrm{T}$ and $\mathrm{R}$. Two membership functions can be defined:

$\operatorname{solved}(\mathrm{T})=\left(k_{1}+k_{2}+\ldots+k_{m}\right) / n, \operatorname{mistaken}(\mathrm{T})=1-\operatorname{solved}(\mathrm{T})$

where $\mathrm{T} \in \mathrm{S}, m$ is the number of accurate results, $k_{i}(1 \leq i \leq m)$ is the weighting factor of the $i$-th task, and $n$ is the number of tasks.

For the level computation two membership functions are also defined: $\operatorname{high}(\mathrm{L})=L, \operatorname{low}(\mathrm{L})=1-\mathrm{L}$, where $\mathrm{L} \in[0,1]$. Only two simple rules will be presented in the knowledgebase of the Fuzzy Expert System:

\section{rule $\mathrm{R} 1$ : if $\mathrm{t}$ is solved then 1 is high and} rule $\mathrm{R} 2$ : if $\mathrm{t}$ is mistaken then 1 is low

where $t$ is an input variable taking values from $S$, and 1 is the output variable.

After the fuzzification process, i.e. applying the solved and mistaken functions on a test $t$ done by the user, the degree of truth for the input variable $\mathrm{t}$ is computed. Afterwards,
PRODUCT-SUM inference is applied on both rules so that two output fuzzy subsets for the output variable 1 are obtained. The PRODUCT-SUM inference is a method of applying the truth value of the premises of every rule to the conclusion part of the corresponding rule, using the PRODUCT function for scaling the output membership function of every rule with the computed truth value of the corresponding premise, and finally applying the SUM function to all output fuzzy subsets assigned to the output variable 1 , in order to obtain a single output fuzzy subset for 1 . At the end, in order to obtain a single crisp value representing the fuzzy subset a defuzzification process is applied on the fuzzy output subset assigned to 1 . The Maximum method is used for defuzzification. The fuzzy logic controller first identifies the scaled membership function with the greatest degree of membership and then determines the typical numerical value for that membership function.

\section{CONCLUSION}

An Integrated Intelligent University Information System IABUIS consisted of the default administrative modules as well as of the formal e-Learning System (eLS) is upgraded with an adaptation functionality in support to steeper student learning curves. The novel integrated system can be considered as an Adaptive e-Learning System (AeLS).

The structure of the AeLS is now consisted of the following three - an eIndex (for student files administration), an eLS (for formal course coverage with learning material) and an additionally integrated CMS (Content Management System) for hosting additional low-budget multimedia supplements. On data-level they all share an integrated Database.

The AeLS introduces an adaptive approach to every individual student, by inferring which supplement (unit or set) is most suitable to support his/her further learning activities. Namely, the core of the AeLS is an existing agent-based interactive context (MMAS) which defines additional roles to the Expert Agent to perform: ranking of the available supplements within a certain course by determining their individual impact (and thus usefulness); fuzzy-based ranking of the students currently enrolled in the course; and configurable (possibly fuzzy-based) matching of the two in order to perform the best possible suggestion of supplement(s) to every single student to ensure steeper learning curve.

All the fuzzy processing and inference is performed by the PFA module and already shows positive results and acceptance by the student community. Further advancement is being worked on and expected as improvement in the adaptation algorithm, as well as in the fuzzy reasoning for the suggestions inference.

\section{REFERENCES}

[1] Cronbach, L..J., \& Snow, R.E. 1977 Aptitudes and Instructional Methods: A handbook for research on interactions, New York: Irvington.

[2] Brusilovsky, P. 1999 "Adaptive hypermedia: from intelligent tutoring systems to web-based education", Künstliche Intelligenz, No. 4, pp 19-25.

[3] Brusilovsky, P. 2001 "Adaptive hypermedia”, User Modeling and User Adapted Interaction, Vol. 11, No. 1/2, pp 87-110.

[4] Brusilovsky, P., and Peylo, C. 2003 "Adaptive and intelligent web-based educational systems", International Journal of Artificial Intelligence in Education, No. 13, pp 156-169. 
[5] Shute, V., and Towle, B. 2003 "Adaptive e-learning", Educational Psychologist, Vol. 38, No. 2, pp 105-114.

[6] Cabukovski, V., and Tusevski, V. 2015 "An Additional Content Development Methodology in an Adaptive Agent Based e-Learning Environment", Proceedings of the European Conference on e-Learning ICEL 2015, ed C Watson, Academic Conferences and Publishing International Limited, pp 58-65.

[7] Cabukovski, V. 2006 "An Agent-Based Testing Subsystem in an E-Learning Environment", Proceedings of the 2006 IEEE/WIC/ACM international conference on Web Intelligence and Intelligent Agent Technology (WIIATW’06), IEEE Computer Society, pp 622-625.

[8] Cabukovski, V. 2010 "An Intelligent eLearning Environment as a Part of an Integrated University Information System", Proceedings of the 9th European Conference on eLearning, Academic Publishing Limited, Vol. 1, pp 90-95.

[9] Cabukovski, V. 2010 "Integrated Agent-Based University Information System", Proceedings of The Second International Conference on Mobile, Hybrid, and OnLine Learning eL\&mL 2010, IEEE Computer Society, pp $36-40$.
[10] Cabukovski, V. 2011 "IABUIS - An Intelligent AgentBased University Information System”, Lecture Notes in Information technology, Information Engineering Research Institute, USA, Vol. 3-4, pp 13-19.

[11] Davcev, D., and Cabukovski, V. 1998 “Agent-based University Intranet and Information System as a Basis for Distance Education and Open Learning”, Proceedings of 1st UICEE Annual Conference on Engineering Education - Globalization of Engineering Education, eds LePP Darvall \& JZ Pudlowski, UNESCO International Centre for Engineering Education (UICEE), pp 253-257.

[12] Cabukovski, V., and Davcev, D. 1998 "MATHEIS (MATHematical Electronic Interactive System): An Agent-Based Distance Educational System for Learning Mathematics", Proceedings International Conference on the Teaching of Mathematics, John Wiley \& Sons, Inc. Publishers, pp 59-61.

[13] Woolridge, M. 2002 Introduction to Multiagent Systems. John Wiley \& Sons, Inc.

[14] Bordini, R.H., Dastani, M., and Dix, J. 2005 Multi-Agent Programming Languages. Platform and Applications, Springer, Berlin. 